\title{
Effect of Silicon Crystal Size on Photoluminescence Appearance in Porous Silicon
}

\author{
Pushpendra Kumar \\ Physik der Kondensierten Materie, TU Braunschweig, 38106 Braunschweig, Germany \\ Correspondence should be addressed to Pushpendra Kumar, pkumar_iitd@yahoo.com \\ Received 31 March 2011; Accepted 16 May 2011 \\ Academic Editor: M. Tommasini
}

Copyright () 2011 Pushpendra Kumar. This is an open access article distributed under the Creative Commons Attribution License, which permits unrestricted use, distribution, and reproduction in any medium, provided the original work is properly cited.

The photoluminescence (PL) study in porous silicon (PS) with decreasing Si crystallites size among the pores was reported. The PL appearance is attributed to electronic confinement in columnar-like (or dotlike) structures of porous silicon. Three different pore diameter PS samples were prepared by electrochemical etching in HF-based solutions. Changes in porous silicon and Si crystallite size were studied by observing an asymmetric broadening and shift of the optical silicon phonons in Raman scattering. Fourier transform infrared spectroscopy (FTIR) was used to study the role of siloxene or other molecular species, for example, $\mathrm{SiH}_{\mathrm{x}}$ in the luminescence mechanism. This mechanism was further studied by thermal annealing of PS at different temperatures. The PL of PS sample annealed at $\geq 300^{\circ} \mathrm{C}$ for $1 \mathrm{hr}$ shows that trap electronic states appear in the energy gap of the smaller nano-crystal when $\mathrm{Si}-\mathrm{O}-\mathrm{Si}$ bonds are formed. From the observation of PL, Raman, and FTIR spectroscopy, the origin of PL in terms of intrinsic and extrinsic properties of nanocrystalline silicon was discussed.

\section{Introduction}

The discovery of photoluminescence in porous silicon (PS) by Canham in 1990 has triggered a large-scale investigation of its use in technological applications, for example, lightemitting diodes [1], light testing equipment [2], photoelectric solar batteries [3], gas testing devices [4], microdevices [5] and biological testing equipment [6]. The physical properties of porous silicon are fundamentally determined by the shape, diameter of pores, porosity, and the thickness of the formed porous layer. Depending on the etching parameters, for example, current density, HF concentration, or substrate doping type and level, the physical properties of PS can be varied [7]. In addition, when the feature size of the pores of PS is less than a few nanometers, various quantum-size effects occur, which make PS even more fascinating. The well-studied PS morphology can range from spongy microporous (pore size $<10 \mathrm{~nm}$ ) and branchy mesoporous silicon (pore size $10-50 \mathrm{~nm}$ ) to the classical macroporous silicon (pore size $50 \mathrm{~nm}-20 \mu \mathrm{m}$ ). Several theories on the formation mechanisms of PS have been reported since its discovery $[8,9]$.
Different models have been reported to explain PL in PS. Quantum confinement is the first model proposed to explain visible photoluminescence from porous silicon [10]. Later, many other alternative models were proposed based on hydrogenated amorphous silicon, surface hydrides, defects, siloxene, and surface states [11, 12]. Except for the quantum confinement model, all the others assume an extrinsic origin of PS luminescence. Brandt et al. [13] have studied PS and siloxene by using Fourier and Raman spectroscopy and shown that the room temperature PL in PS is not an intrinsic property of crystalline silicon (quantum confinement effect) but depends on specific chemical reactions of silicon with hydrogen and oxygen. These observations have further been supported by Fuchs et al. [14]. Gorbach et al. [15] supported the view that chemical passivation in PS, in particular by oxygen, is the major factor which controls the origin of PL by using the simultaneous investigation of PL, FTIR absorption, and SEM observation of PS. Many theoretical [16] and experimental $[17,18]$ reports suggest that quantum confinement is most effective to explain PL in PS. However, there is still an important challenge to understand the optical properties of a PS material in terms of its fundamental 
physics. To discriminate the different approaches (i.e., quantum confinement or siloxene or some other species in PS) to explain PL in PS various methods can be used. One of them is the study of the behavior of PL spectrum under variation of Si crystallites sizes. To further explore the physics behind the origin of PL in PS, we have studied systematically the appearance of PL in PS with decreasing (or increasing the pore diameter) the Si nanocrystallites size among the pores by using Raman, PL, and FTIR spectroscopy.

\section{Experimental Details}

PS layers were prepared by electrochemical anodic etching of a highly doped $p$-type $\langle 100\rangle$-oriented silicon substrate with a resistivity of $0.01-0.02 \Omega \mathrm{cm}$. The electrochemical cell was made of Teflon and the base plate was made of aluminum. A silicon wafer was mounted at the base plate by using an $O$ ring that allowed $7.0 \mathrm{~cm}^{2}$ of the $S i$ surface to be exposed to the electrolytes. The later consist of three different concentration of $3: 7,4: 6$, and $6: 4$ by volume $48 \%$ hydrofluoric acid (HF): $98 \%$ ethanol, respectively. Prior to each experiment, the Si wafers were ultrasonically cleaned in propanol and acetone. The etching current density $14.5 \mathrm{~mA} / \mathrm{cm}^{2}$ was applied for $30 \mathrm{~min}$. The thicknesses of the porous layers determined with an optical microscope were in the range of $20-25 \mu \mathrm{m}$. The physical properties (i.e., pore diameter $\left(D_{P}\right)$ and the porosity $(\Phi))$ of PS samples were determined by recording a volumetric nitrogen sorption isotherms at $T=77 \mathrm{~K}$ in a homemade all-metal gas handling system that is equipped with a membrane pressure gauge of $1000 \mathrm{mbar}$ full scale [19]. The PL measurements were done using a Hamamatsu TGSWNIR, C9405CA spectrometer and a laser diode exciting the sample at a wavelength of $405 \mathrm{~nm}$. Raman scattering experiments were performed using the excitation line $\lambda=$ $532 \mathrm{~nm}$ of a semiconductor laser in quasibackscattering geometry. The laser power of $5 \mathrm{~mW}$ was focused to a $0.1 \mathrm{~mm}$ diameter spot on the PS surface. The scattered spectra were collected by a DILOR-XY triple spectrometer and a nitrogencooled charge-coupled device detector. For the measurements, the samples were placed in a sample chamber which was evacuated or, alternatively, filled with helium gas in order to suppress the low frequency Raman scattering by air and to prevent possible laser-induced oxidation of the PS layers. Since the PS provides a large surface area [20], therefore it has been extensively studied by FTIR to study surface species [21]. A FTIR (Perkin Elmer, system 2000 FT-IR) spectroscopy was used to measure molecular vibrational excitations in PS. To improve the statistics, data of 51 spectra were averaged with a resolution of $4 \mathrm{~cm}^{-1}$. For the FTIR study, free-standing PS layers were used to study the chemical species, as the highly doped bulk silicon wafers are not transparent for the IR light. After etching of silicon for $30 \mathrm{~min}$, the porous layers were detached from the silicon substrate by a sudden increase in applied current for $60 \mathrm{~s}$.

\section{Results and Discussion}

The physical properties of PS can be varied by changing the etching parameters, for example current density, HF concentration, or substrate doping type and level [7]. In the present case, we have varied the HF concentration to change the pore diameter and porosity. The three different HF concentration, that is, 30\% HF: $70 \%$ ethanol, $40 \%$ HF: $60 \%$ ethanol and 60\% HF: $40 \%$ ethanol during etching of Si were used to prepare the PS sample a, b, and c respectively. The pore diameter and porosity of PS was found to decrease with an increase of the HF concentration in the used etching electrolyte at constant applied current density. Theoretical and experimental details concerning this effect have been reported by some groups $[22,23]$. In our work, we report that the photoluminescence appearance in PS with increase in pore diameter (i.e., decrease in Si crystallite size among the pores) is due to quantum confinement by using aforementioned techniques.

3.1. Si Nanocrystallites Size Determination and Phonon Dynamics in PS. Raman spectroscopy, which is a sensitive probe to the local atomic arrangements and vibrations, has been used to characterize PS [24] and Si nanostructures [25]. The shift and half-width of the one-phonon Raman peak in c-Si has often been used to obtain an estimate of the characteristic dimensions of the Si crystallites. To characterize and interpret the Raman spectra of semiconductor nanostructures, a phenomenological phonon confinement model $[26,27]$ has been widely used. This model, originally proposed by Richter, Wang, and Ley (RWL model) [26], has been found to be useful for accounting for the peak-position shift, broadening, and asymmetry of bands observed in nanocrystalline $\mathrm{Si}$, [25] Ge [28], and GaAs [29]. The Raman shift due to the confinement can be described by a phenomenological approach that is based on the negative dispersion of optical phonons with finite momentum and the averaging and folding of phonon frequencies in small particles. An analytic form of this approach to describe the Raman frequency shift as also used by Paillard et al. [30] is

$$
\Delta \omega=-A\left(\frac{a}{L}\right)^{\gamma}
$$

where $a=0.543 \mathrm{~nm}$ is the lattice constant of Si, $L$ is the crystallites size, the parameters $A=52.3$, and $\gamma=1.586$ are used to describe the vibrational confinement due to the finite size in a nanocrystal and depend on the investigated system. By using this equation we have calculated the crystallites size of $\mathrm{Si}$ among the pores. In Figure 1 we show the phonon frequency of porous silicon samples a, b, and c. A peak shift was observed from 519 to $516 \mathrm{~cm}^{-1}$ and a broadening of the peak width full width at half maximum (FWHM) from 4.2 (symmetric) to $8.3 \mathrm{~cm}^{-1}$ (asymmetric) with an increase in pore diameter $\left(D_{P}\right)$ from $3 \mathrm{~nm}$ to $10 \mathrm{~nm}$, respectively. The shift of the phonon peak towards lower wavenumber and broadening of the peak width with increase in pore diameter and porosity are attributed to the confinement of optical phonons in nanodimensional Si crystals among the pores $[27,31]$. The shift of the phonon peak was used to calculate the crystallites size of $\mathrm{Si}$ in sample $\mathrm{a}, \mathrm{b}$, and $\mathrm{c}$ by using above equation. The calculated crystallites size of $\mathrm{Si}$ and other physical properties of PS samples are listed in Table 1. With 


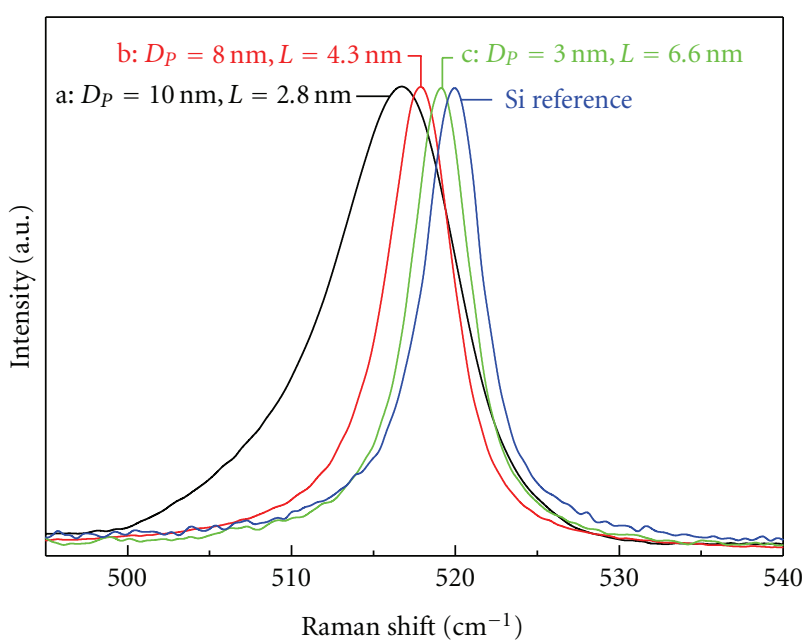

Figure 1: Raman spectra of bulk Si and PS samples a, b, and c. $D_{P}$ is pore diameter and $L$ is the crystallites size of $\mathrm{Si}$ among the pores.

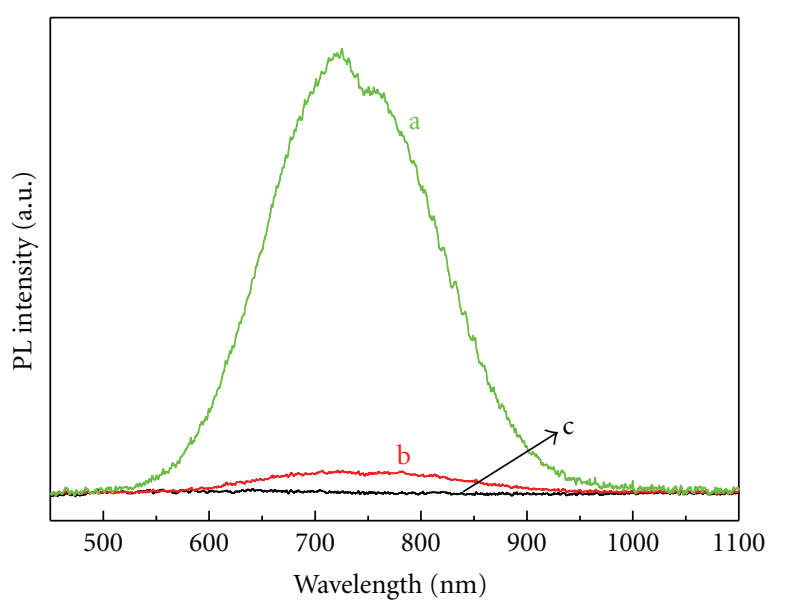

a: $L=2.8 \mathrm{~nm}$

b: $L=4.3 \mathrm{~nm}$

c: $L=6.6 \mathrm{~nm}$

FIGURE 2: Photoluminescence of PS samples a, b, and c.

increase in pore diameter from $3 \mathrm{~nm}$ to $10 \mathrm{~nm}$ the nanocrystallites size of $\mathrm{Si}$ among the pores decreases from $6.6 \mathrm{~nm}$ to $2.8 \mathrm{~nm}$ respectively. When the crystallites size of Si approaches the dimension of a free exciton (i.e., $5 \mathrm{~nm}$ ) of bulk $\mathrm{Si}$ the photoluminescence starts to appear which is discussed in next section.

3.2. Photoluminescence Appearance in PS. Photoluminescence and Raman spectra of porous silicon give the information of a cross-sectional view of the silicon nanocrystallites which remains among the pores, because of the large optical penetration depth. Photoluminescence is directly related to the electronic structure and transitions. The characteristic change of the band gap with decrease in size of the nanostructures can be studied by the observation of the blue shift in the photoluminescence peak position [32]. Thus,

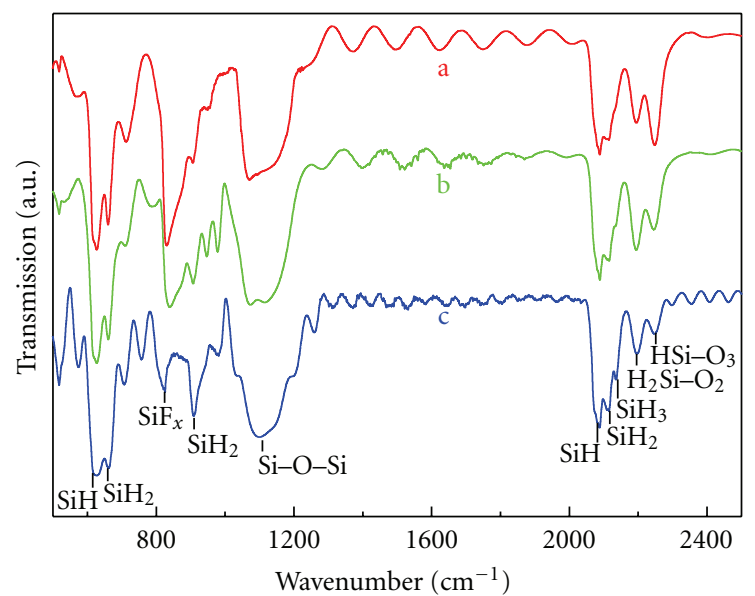

FIGURE 3: FTIR spectra of PS samples a, b, and c.

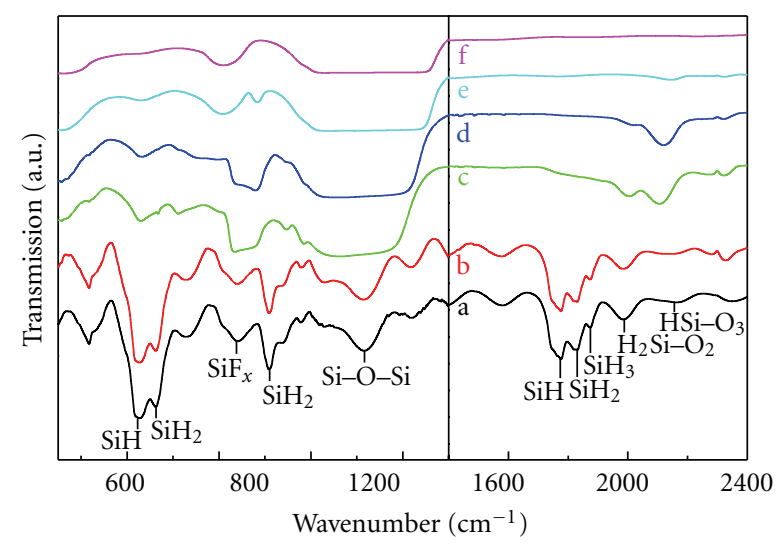

FIGURE 4: FTIR spectra of PS sample (a) fresh PS and annealed for $1 \mathrm{hrs}$ at different temperature, (b) $100^{\circ} \mathrm{C}$, (c) $200^{\circ} \mathrm{C}$, (d) $300^{\circ} \mathrm{C}$, (e) $400^{\circ} \mathrm{C}$, and (f) $500^{\circ} \mathrm{C}$.

photoluminescence is useful in the study of quantum confinement of electrons in low-dimensional materials [33]. In Figures 2(a)-2(c) we show PL spectra of sample a, b, and c. It can be seen from Figure 2 that with decrease in $\mathrm{Si}$ nanocrystallites size the photoluminescence starts to appear and increases in intensity. In Figure 2(b) we can see a small intensity of PL peak while in sample a as shown in Figure 2(a) we see a strong PL peak around at $735 \mathrm{~nm}$. Bulk silicon has an indirect band gap and does not show any photoluminescence peak while porous silicon shows a photoluminescence peak at around $750 \mathrm{~nm}$. When the Si crystallites size is reduced to $2.8 \mathrm{~nm}$, much smaller than the dimension of free excitons, a strong quantum confinement in Si nanostructure starts to occur leading to the appearance of photoluminescence. Several mechanisms have been suggested to explain the appearance of this luminescence signal, such as defects that localize carriers at extrinsic centers or surface states providing radiative recombination centers, surface hydrides $\left(\mathrm{SiH}_{\mathrm{x}}\right.$ groups) or the formation of siloxane (a $\mathrm{Si}-\mathrm{O}-\mathrm{H}$ based polymer), or quantum-confinement effects of the excitons caused by their spatial confinement within Si-nanocrystallites. The latter mechanism was proven to be the origin of the observed 
TABLE 1: Variation of physical properties as a function of HF concentration and corresponding Si crystallites size of sample a, b, and c.

\begin{tabular}{lcccccc}
\hline Sample details & $\begin{array}{c}\text { Electrolyte } \\
(\text { HF }: \text { ethanol })\end{array}$ & $\begin{array}{c}\text { Pore dia. } \\
(\mathrm{nm})\end{array}$ & $\begin{array}{c}\text { Porosity } \\
\%\end{array}$ & $\begin{array}{c}\text { Peak width } \\
\mathrm{cm}^{-1}\end{array}$ & $\begin{array}{c}\text { Phonon frequency shift } \\
\mathrm{cm}^{-1}\end{array}$ & $\begin{array}{c}\text { Si crystallites size } \\
(\mathrm{nm})\end{array}$ \\
\hline a & $3: 7$ & 10 & 54 & 8.3 & -4 & 2.8 \\
b & $4: 6$ & 8 & 45 & 4.9 & -2 & 4.3 \\
c & $6: 4$ & 3 & 30 & 4.2 & -1 & 6.6 \\
\hline
\end{tabular}

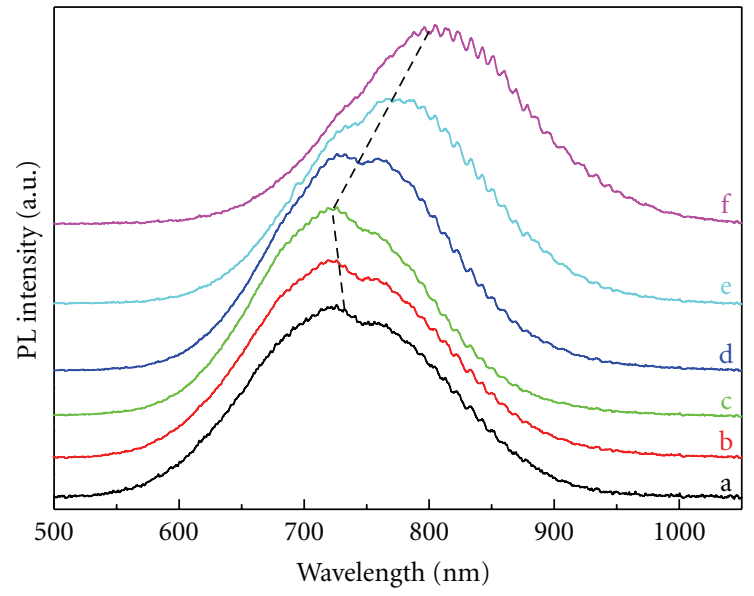

Figure 5: PL spectra of PS sample (a) fresh PS and annealed for $1 \mathrm{hrs}$ at different temperature, (b) $100^{\circ} \mathrm{C}$, (c) $200^{\circ} \mathrm{C}$, (d) $300^{\circ} \mathrm{C}$, (e) $400^{\circ} \mathrm{C}$, and (f) $500^{\circ} \mathrm{C}$.

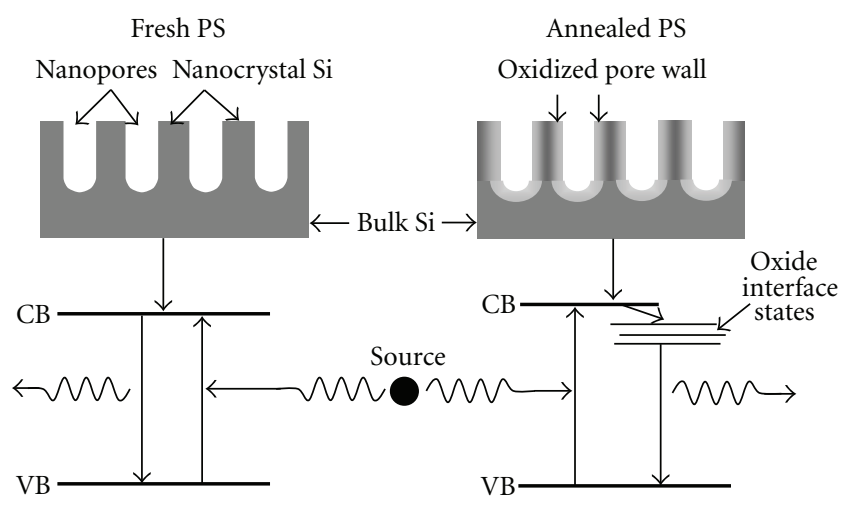

FIGURE 6: Schematic diagram of fresh PS and annealed PS and their corresponding energy levels.

luminescence. There is still the discussion open on the mechanism of PL in PS. The absence of PL from sample c indicates that porous silicon with the Si crystallites size of $6.6 \mathrm{~nm}$ behaves similar to bulk silicon. The absence of PL signal from sample $\mathrm{c}$ and a strong signal from sample a indicates that the quantum confinement effect in the narrow silicon regime between two pores results in a strong PL signal. To exclude an effect of other chemical species, for example, $\mathrm{SiH}_{\mathrm{x}}$, siloxene, and so forth, we have carried out FTIR measurement of all three PS samples.

3.3. Chemical Species in PS. In Figure 3 we show transmission FTIR spectra of all three PS samples. The spectrum of PS sample exhibits a Si-H bending mode at $630 \mathrm{~cm}^{-1}$, a $\mathrm{Si}-\mathrm{H}_{2}$ wagging mode at $680 \mathrm{~cm}^{-1}$ and a $\mathrm{Si}-\mathrm{H}$ scissor mode at $910 \mathrm{~cm}^{-1}$. The presence of an absorption peak around $1100 \mathrm{~cm}^{-1}$ which is assigned to the $\mathrm{Si}-\mathrm{O}-\mathrm{Si}$ antisymmetric stretching mode in as prepared PS sample, indicates that the PS layer is already partially oxidized while transferring the sample from the etching cell to the FTIR setup [34, 35]. The structure in the spectrum located between 2050 and $2150 \mathrm{~cm}^{-1}$ correspond to silicon hydride species while those between 2150 and $2300 \mathrm{~cm}^{-1}$ corresponds to silicon oxyhydride species. The three strong absorption peaks at 2090, 2110 , and $2140 \mathrm{~cm}^{-1}$ are associated with Si-H, Si$\mathrm{H}_{2}$, and $\mathrm{Si}-\mathrm{H}_{3}$ vibrational stretching modes, respectively. The absorption lines at 2195 and $2250 \mathrm{~cm}^{-1}$ are attributed to $\mathrm{H}_{2} \mathrm{Si}-\mathrm{O}_{2}$ and $\mathrm{HSi}-\mathrm{O}_{3}$ bonding, respectively. The peaks assigned in Figure 3 are in good agreement with data reported in the literature $[36,37]$. It is interesting to point out that no clear difference in the FTIR spectra can be found in Figure 3 between all three PS samples. This means that the light emission in porous materials are in no relation to extrinsic origins or effects, such as hydrogenated amorphous $\mathrm{Si}$, surface hydrides, defects in $\mathrm{Si}$ or $\mathrm{SiO}_{\mathrm{x}}$, siloxene, or surface states. To further survey the effect of these species, we annealed the sample (a) at different temperature up to $500^{\circ} \mathrm{C}$ for $1 \mathrm{hrs}$ and measured the FTIR and photoluminescence.

3.4. Thermal Annealing of PS. In Figure 4 we show the FTIR spectra of thermally annealed PS. From the spectra it is clearly seen that most of the molecular species desorbs at $500^{\circ} \mathrm{C}$. The corresponding photoluminescence of thermally annealed PS at different temperature can be seen in Figure 5. Except small change in peak position and intensity the PL is still observed, which further proves that PL in PS with the crystallites size of $2.8 \mathrm{~nm}$ is not related to the external species. The initial change in peak position of PL till the annealing temperature of $200^{\circ} \mathrm{C}$ was blue shifted, which can be understood that the surface-oxidation-induced reduction of the particle sizes leads to higher PL peak energies. But on further increase in annealing temperature the red shift in the PL spectra was observed. The red as well as blue PL peak position shift in PS with increase in thermal annealing temperature has been reported by several researchers. Roy et al. has reported the similar observations that the PL peak in PS with increase in annealing temperature shows first blue shift and then red shift. They have attributed their observation to the hybrid model in which both quantum confinement and luminescence centres outside the nanoscale unit has been accounted [38]. Recently Huang et al. have reported theoretical calculation where they showed that the 
trap electronic states appear in the energy gap of the smaller nanocrystal $\mathrm{Si}$ on thermal annealing when $\mathrm{Si}=\mathrm{O}$ bonds or $\mathrm{Si}-\mathrm{O}-\mathrm{Si}$ bonds are formed [39]. In the present study, the red shift in PL peak of PS can be understood as follows. In Figure 4 it can be seen that the pore surface initially saturated by the hydrogen atoms, and during the oxidation process they are gradually substituted by oxygen atoms. When the annealing temperature is $\geq 300^{\circ} \mathrm{C}$ the oxides layer on porous $\mathrm{Si}$ nanocrystal formed. When nanocrystalline $\mathrm{Si}$ is oxidized, the $\mathrm{Si}-\mathrm{Si}$ bonds are likely to weaken or break because of large stress at the distortion surface. Then the $\mathrm{Si}-\mathrm{O}-\mathrm{Si}$ bonds is more likely to be formed and stabilized the interface, since it requires neither large deformation energy nor an excess element, while the localized trap states are formed in band gap gradually. A schematic diagram showing oxide formation on pore walls and their corresponding localized states formation due to $\mathrm{Si}-\mathrm{O}-\mathrm{Si}$ bonds are shown in Figure 6. The present observation of the red shift in PL peak position on thermal annealing are in agreement with the theoretical model about the trap electronic states in nanocrystal Si reported by Huang et al. [39].

\section{Conclusions}

The Si crystallites size was varied in PS by changing the HF concentration in etching electrolytes. Photoluminescence was observed when the crystallite size of $\mathrm{Si}$ was reduced to smaller than the dimension of free exciton of bulk Si. The $\mathrm{PL}$ appearance in PS is attributed to quantum confinement and not to external molecular species. The effect of external species was studied with the help of FTIR and further verified by the annealing of PS. The red shift in PL peak of thermally annealed PS was observed due to the localized states in band gap. Our investigation will furthermore be useful for the researcher to understand the phenomena of PL in PS.

\section{Acknowledgment}

The author gratefully acknowledge Technische Physik, Universität des Saarland for providing the FTIR measurement facilities.

\section{References}

[1] A. Richter, P. Steiner, F. Kozlowski, and W. Lang, "Currentinduced light emission from a porous silicon device," IEEE Electron Device Letters, vol. 12, no. 12, pp. 691-692, 1991.

[2] G. Smestad, M. Kunst, and C. Vial, "Photovoltaic response in electrochemically prepared photoluminescent porous silicon," Solar Energy Materials and Solar Cells, vol. 26, no. 4, pp. 277283, 1992.

[3] G. Willeke, H. Nussbaumer, H. Bender, and E. Bucher, "A simple and effective light trapping technique for polycrystalline silicon solar cells," Solar Energy Materials and Solar Cells, vol. 26, no. 4, pp. 345-356, 1992.

[4] J. P. Proot, C. Delerue, and G. Allan, "Electronic structure and optical properties of silicon crystallites: application to porous silicon," Applied Physics Letters, vol. 61, no. 16, pp. 1948-1950, 1992.
[5] H. Lehmann, "Interplay of structures and forces in the electronic conductivity of liquid mercury," Physics and Chemistry of Liquids, vol. 28, no. 4, pp. 245-252, 1996.

[6] A. Janshoff, K.-P. Dancil, C. Steinem et al., "Macroporous ptype silicon Fabry-Perot layers. Fabrication, characterization, and applications in biosensing," Journal of the American Chemical Society, vol. 120, no. 46, pp. 12108-12116, 1998.

[7] R. Herino, G. Bomchil, K. Barla, C. Bertrand, and J. L. Ginoux, "Porosity and pore size distributions of porous silicon layers," Journal of the Electrochemical Society, vol. 134, no. 8, pp. 19942000, 1987.

[8] R. L. Smith and S. D. Collins, "Porous silicon formation mechanisms," Journal of Applied Physics, vol. 71, no. 8, pp. R1R22, 1992.

[9] R. L. Smith, S. F. Chuang, and S. D. Collins, "A theoretical model of the formation morphologies of porous silicon," Journal of Electronic Materials, vol. 17, no. 6, pp. 533-541, 1988.

[10] L. T. Canham, "Silicon quantum wire array fabrication by electrochemical and chemical dissolution of wafers," Applied Physics Letters, vol. 57, no. 10, pp. 1046-1048, 1990.

[11] S. Ossicini, L. Pavesi, and F. Priolo, Light Emitting Silicon for Microphotonics, Springer, Berlin, Germany, 2003.

[12] A. G. Cullis, L. T. Canham, and P. D. J. Calcott, "The structural and luminescence properties of porous silicon," Journal of Applied Physics, vol. 82, no. 3, pp. 909-965, 1997.

[13] M. S. Brandt, H. D. Fuchs, M. Stutzmann, J. Weber, and M. Cardona, "The origin of visible luminescencefrom "porous silicon": a new interpretation," Solid State Communications, vol. 81, no. 4, pp. 307-312, 1992.

[14] H. D. Fuchs, M. Stutzmann, M. S. Brandt et al., "Porous silicon and siloxene: vibrational and structural properties," Physical Review B, vol. 48, no. 11, pp. 8172-8189, 1993.

[15] T. Y. Gorbach, G. Y. Rudko, P. S. Smertenko et al., "Simultaneous changes in the photoluminescence, infrared absorption and morphology of porous silicon during etching by HF," Semiconductor Science and Technology, vol. 11, no. 4, pp. 601606, 1996.

[16] G. C. John and V. A. Singh, "Theory of the photoluminescence spectra of porous silicon," Physical Review B, vol. 50, no. 8, pp. 5329-5334, 1994.

[17] L. Jia, S. L. Zang, S. P. Wong et al., "Further evidence for the quantum confined electrochemistry model of the formation mechanism of p-type porous silicon," Applied Physics Letters, vol. 69, no. 22, pp. 3399-3401, 1996.

[18] V. Lehmann and U. Gosele, "Porous silicon: quantum sponge structures grown via a self-adjusting etching process," Advanced Materials, vol. 4, no. 2, pp. 114-116, 1992.

[19] P. Kumar, P. Lemmens, M. Ghosh, F. Ludwig, and M. Schilling, "Effect of HF concentration on physical and electronic properties of electrochemically formed nanoporous silicon," Journal of Nanomaterials, vol. 2009, Article ID 728957, 7 pages, 2009.

[20] P. Kumar and P. Huber, "Quenching of reducing properties of mesoporous silicon and its use as template for metal/semiconductor deposition," Journal of the Electrochemical Society, vol. 157, no. 3, pp. D172-D176, 2010.

[21] P. O. Keeffe, Y. Aoyagi, S. Komuro, T. Kato, and T. Morikawa, "Room-temperature backbond oxidation of the porous silicon surface by oxygen radical irradiation," Applied Physics Letters, vol. 66, p. 836, 1995.

[22] X. G. Zhang, S. D. Collins, and R. L. Smith, "Porous silicon formation and electropolishing of silicon by anodic 
polarization in HF solution," Journal of the Electrochemical Society, vol. 136, no. 5, pp. 1561-1565, 1989.

[23] X. G. Zhang, "Mechanism of pore formation on n-type silicon," Journal of the Electrochemical Society, vol. 138, no. 12, pp. 3750-3756, 1991.

[24] Z. Sui, P. P. Leong, I. P. Herman, G. S. Higashi, and H. Temkin, "Raman analysis of light-emitting porous silicon," Applied Physics Letters, vol. 60, no. 17, pp. 2086-2088, 1992.

[25] S. Furukawa and T. Miyasato, "Quantum size effects on the optical band gap of microcrystalline Si:H," Physical Review B, vol. 38, no. 8, pp. 5726-5729, 1988.

[26] H. Richter, Z. P. Wang, and L. Ley, "The one phonon Raman spectrum in microcrystalline silicon," Solid State Communications, vol. 39, no. 5, pp. 625-629, 1981.

[27] I. H. Campbell and P. M. Fauchet, "The effects of microcrystal size and shape on the one phonon Raman spectra of crystalline semiconductors," Solid State Communications, vol. 58, no. 10, pp. 739-741, 1986.

[28] T. Kanata, H. Murai, and K. Kubota, "Raman and x-ray scattering from ultrafine semiconductor particles," Journal of Applied Physics, vol. 61, no. 3, pp. 969-972, 1986.

[29] K. K. Tiong, P. M. Amirtharaj, F. H. Pollak, and D. E. Aspnes, "Effects of $\mathrm{As}^{+}$ion implantation on the Raman spectra of GaAs: "spatial correlation" interpretation," Applied Physics Letters, vol. 44, no. 1, pp. 122-124, 1984.

[30] V. Paillard, P. Puech, M. A. Laguna, R. Carles, B. Kohn, and F. Huisken, "Improved one-phonon confinement model for an accurate size determination of silicon nanocrystals," Journal of Applied Physics, vol. 86, no. 4, pp. 1921-1924, 1999.

[31] Z. Sui, P. P. Leong, I. P. Herman, G. S. Higashi, and H. Temkin, "Raman analysis of light-emitting porous silicon," Applied Physics Letters, vol. 60, no. 17, pp. 2086-2088, 1992.

[32] P. Moriarty, "Nanostructured materials," Reports on Progress in Physics, vol. 64, no. 3, pp. 297-381, 2001.

[33] A. K. Sood, K. Jayaram, and D. V. S. Muthu, "Raman and high-pressure photoluminescence studies on porous silicon," Journal of Applied Physics, vol. 72, no. 10, pp. 4963-4965, 1992.

[34] Y. H. Ogata, N. Yoshimi, R. Yasuda, T. Tsuboi, T. Sakka, and A. Otsuki, "Structural change in p-type porous silicon by thermal annealing," Journal of Applied Physics, vol. 90, no. 12, pp. 64876492, 2001.

[35] P. Kumar and P. Huber, "Nucleation and growth of copper on mesoporous silicon by immersion plating," Journal of Physics D: Applied Physics, vol. 40, no. 9, pp. 2864-2869, 2007.

[36] Y. K. Xu and S. Adachi, "Light-emitting porous silicon formed by photoetching in aqueous HF/KIO 3 solution," Journal of Physics D: Applied Physics, vol. 39, no. 21, pp. 4572-4577, 2006.

[37] P. Kumar, T. Hofmann, K. Knorr, P. Huber, P. Scheib, and P. Lemmens, "Tuning the pore wall morphology of mesoporous silicon from branchy to smooth, tubular by chemical treatment," Journal of Applied Physics, vol. 103, no. 2, Article ID 024303, 2008.

[38] A. Roy, K. Jayaram, and A. K. Sood, "Raman and photoluminescence studies on thermally annealed porous silicon," Solid State Communications, vol. 89, no. 3, pp. 229-233, 1994.

[39] W.-Q Huang, F. Jin, H.-X Wang, L. Xu et al., "Stimulated emission from trap electronic states in oxide of nanocrystal Si," Applied Physics Letters, vol. 92, no. 22, Article ID 221910, 2008. 

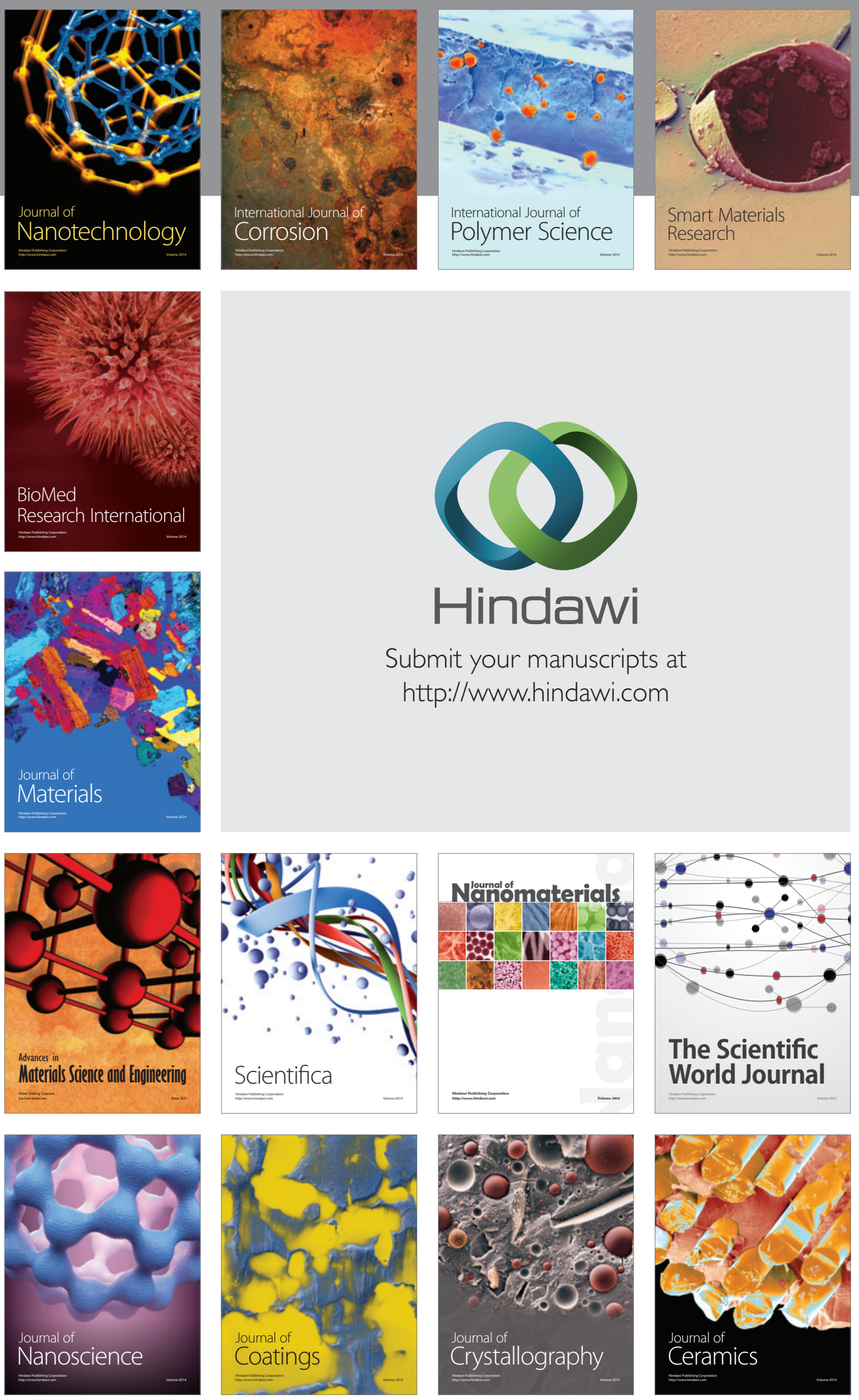

The Scientific World Journal

Submit your manuscripts at

http://www.hindawi.com

\section{World Journal}

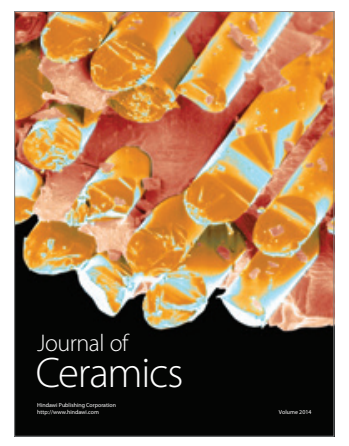

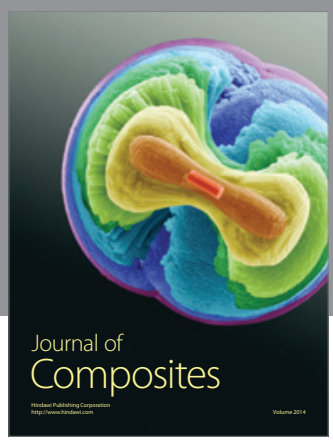
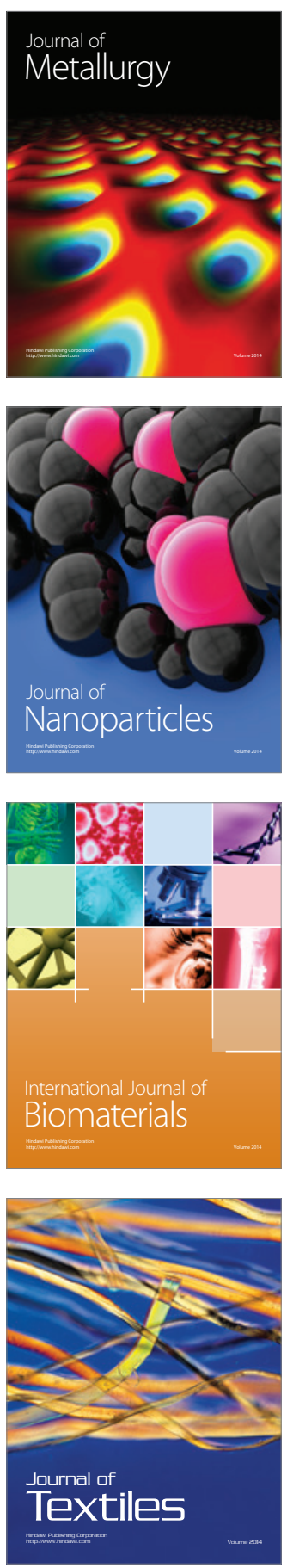